\title{
Magnetically Directed Assembly of Nanocrystals for Catalytic Control of a Three-Component Coupling Reaction
}

Alaa M. Munshi, ${ }^{a}$ Vipul Agarwal, ${ }^{a}$ Dominic Ho, ${ }^{a}$ Colin L. Raston, ${ }^{b}$ Martin Saunders, ${ }^{c}$ Nicole M. Smith, ${ }^{a} *$ and K. Swaminathan Iyer ${ }^{a} *$

\section{Supporting Information}

\section{Materials:}

Chloroauric acid $\left(\mathrm{HAuCl}_{4}\right)$, sodium borohydride $\left(\mathrm{NaBH}_{4}\right)$, Iron(II) sulfate heptahydrate $\left(\mathrm{FeSO}_{4} \cdot 7 \mathrm{H}_{2} \mathrm{O}\right)$, piperidine, phenylacetylene and polyethyleneimine (PEI, branched, $\mathrm{Mw} \approx$ 25,000 $\left.\mathrm{g} \mathrm{mol}^{-1}\right)$ were obtained from Sigma-Aldrich, Australia. Potassium nitrate $\left(\mathrm{KNO}_{3}\right)$, sodium citrate $\left(\mathrm{C}_{6} \mathrm{H}_{5} \mathrm{Na}_{3} \mathrm{O}_{7} . \mathrm{H}_{2} \mathrm{O}\right)$ and benzaldehyde were obtained from Ajax Finechem, Australia. Sodium hydroxide $(\mathrm{NaOH})$ was obtained Fluka, Australia. Hydroxylamine hydrochloride $\left(\mathrm{NH}_{2} \mathrm{OH} . \mathrm{HCl}\right)$ was obtained from VWR, Australia. All chemicals were used as received with no further purification.

The Au-coated $\mathrm{Fe}_{3} \mathrm{O}_{4}$ nanoparticles $\left(\mathrm{Fe}_{3} \mathrm{O}_{4} @ \mathrm{Au}\right)$ catalyst was prepared using a previously reported multistep process. ${ }^{1}$

\section{Synthesis of PEI-coated $\mathrm{Fe}_{3} \mathrm{O}_{4}$ nanoparticles $\left(\mathrm{Fe}_{3} \mathrm{O}_{4}\right.$-PEI):}

Briefly, $\mathrm{Fe}_{3} \mathrm{O}_{4}$ nanoparticles were synthesized by dissolving $\mathrm{FeSO}_{4} .7 \mathrm{H}_{2} \mathrm{O}(1.3 \mathrm{~g})$ in Milli-Q water $(80 \mathrm{~mL})$ under a nitrogen atmosphere, followed by the addition of $\mathrm{NaOH}(10 \mathrm{~mL}, 1.0$ M) and $\mathrm{KNO}_{3}(10 \mathrm{~mL}, 2.0 \mathrm{M})$. The resulting $\mathrm{Fe}(\mathrm{OH})_{2}$ was subsequently heated at $90{ }^{\circ} \mathrm{C}$ for 2 hours with the simultaneous addition of different concentrations of PEI solution ( 0 to $4 \mathrm{~g} / \mathrm{L})$ in order to get PEI coated $\mathrm{Fe}_{3} \mathrm{O}_{4}$ nanoparticles. The nanoparticles were cooled to room temperature and magnetically separated using an external magnet followed by multiple washing steps to remove excess PEI. The resulting purified nanoparticles were dispersed in Milli-Q water $(80 \mathrm{~mL})$ and stored until further use. 


\section{Preparation of Au-Seed:}

A colloidal solution of Au seeds was prepared by adopting a previously reported procedure by Brown et al. ${ }^{2}$ Briefly, $\mathrm{HAuCl}_{4}\left(1 \mathrm{~mL}, 1 \% \mathrm{v} / \mathrm{v}\right.$ in $\left.90 \mathrm{~mL} \mathrm{H} \mathrm{H}_{2} \mathrm{O}\right)$ was stirred with sodium citrate $(2 \mathrm{~mL}, 38.8 \mathrm{mM})$, followed by the addition of $\mathrm{NaBH}_{4}(1 \mathrm{~mL}, 0.075 \% \mathrm{w} / \mathrm{v})$ and the resulting mixture was left at room temperature with stirring for an additional five minutes.

\section{Synthesis of $\mathrm{Au}$ seed functionalised $\mathrm{Fe}_{3} \mathrm{O}_{4}$-PEI nanoparticles:}

PEI-coated $\mathrm{Fe}_{3} \mathrm{O}_{4}$ nanoparticles $(2 \mathrm{~mL}$ in water) were stirred with a freshly synthesized $\mathrm{Au}$ seed solution $(90 \mathrm{~mL})$ for 2 hours. The resulting $\mathrm{Au}$ seed functionalised $\mathrm{Fe}_{3} \mathrm{O}_{4}$-PEI nanoparticles were separated using an external magnet and washed multiple times with MilliQ water. The nanoparticle surface was further functionalized with PEI $(5 \mathrm{~g} / \mathrm{L})$ by heating the reaction mixture at $60{ }^{\circ} \mathrm{C}$ for 1 hour. Subsequently, the particles were further washed with Milli-Q water $(5 \times)$ and were then redispersed in Milli-Q water $(20 \mathrm{~mL})$.

\section{Synthesis of Au-coated $\mathrm{Fe}_{3} \mathrm{O}_{4}$ Nanoparticles $\left(\mathrm{Fe}_{3} \mathrm{O}_{4} @ \mathrm{Au}\right)$ :}

$\mathrm{Au}$ seed functionalised $\mathrm{Fe}_{3} \mathrm{O}_{4}$-PEI nanoparticles $(20 \mathrm{~mL})$ were added to a $\mathrm{NaOH}$ solution $(110 \mathrm{~mL}, 0.01 \mathrm{M})$ with constant stirring. Following which $\mathrm{NH}_{2} \mathrm{OH} . \mathrm{HCl}(0.75 \mathrm{~mL}, 0.2 \mathrm{M})$ and $\mathrm{HAuCl}_{4}(1 \% \mathrm{v} / \mathrm{v}, 0.5 \mathrm{~mL})$ were added to the reaction mixture. This was then followed by multiple $(4 \times)$ additions of $\mathrm{NH}_{2} \mathrm{OH} . \mathrm{HCl}(0.25 \mathrm{~mL}, 0.2 \mathrm{M})$ and $\mathrm{HAuCl}_{4}(1 \% \mathrm{v} / \mathrm{v}, 0.5 \mathrm{~mL})$ in 10 minute intervals and the resulting mixture was left to react for 1 hour. The $\mathrm{Au}$-coated $\mathrm{Fe}_{3} \mathrm{O}_{4}$ nanoparticles were then separated magnetically from the mixture, washed water $(5 \times)$, dispersed in Milli-Q water $(20 \mathrm{~mL})$ and stored at room temperature until further use. Inductively coupled plasma (ICP) analysis confirmed the concentration of $\mathrm{Au}(0.57 \mathrm{mg} / \mathrm{L})$ and $\mathrm{Fe}(1600 \mathrm{mg} / \mathrm{L})$ in the synthesized catalyst.

\section{Fabrication of $\mathrm{Fe}_{3} \mathrm{O}_{4} @$ Au nanowires:}

$\mathrm{Fe}_{3} \mathrm{O}_{4} @ \mathrm{Au}$ nanowires were fabricated using a previously reported method developed in our lab. ${ }^{3}$ Briefly, $2 \mathrm{NdFeB}$ magnets $(5 \times 5 \times 2 \mathrm{~cm}$ and $4.5 \times 3 \times 1 \mathrm{~cm})$ with their field directions aligned were placed on two sides of the parallel reactor with the reaction test tube equidistant from both magnets. The resulting nanowires were characterized and quantified using transmission electron microscopy (TEM). 


\section{Transmission Electron Microscopy (TEM):}

Nanoparticles were air dried on carbon-coated copper grids and imaged using a JEOL 2100 TEM operating at an accelerating voltage of $120 \mathrm{kV}$. Nanoparticle size was determined using ImageJ software (NIH, USA). A minimum of 200 nanoparticles was measured and the data is reported as an average \pm standard error mean. High-angle annular dark-field (HAADF) scanning transmission electron microscope (STEM) images, Energy-dispersive X-ray spectroscopy (EDX) - point mode (elemental analysis) and mapping mode (elemental maps) were obtained on the FEI Titan G2 80-200 TEM/STEM operating at an accelerating voltage of $200 \mathrm{kV}$.

\section{Powder X-ray diffraction analysis (XRD):}

$\mathrm{Fe}_{3} \mathrm{O}_{4} @ \mathrm{Au}$ nanoparticles were dried and analyzed using a PANalytical Empyrean XRD with $\mathrm{Cu} \mathrm{K} \alpha$ radiation $(\lambda=1.54 \AA)$ operated at an emission current and a generator voltage of 40 $\mathrm{mA}$ and $40 \mathrm{kV}$, respectively to analyze the crystalline phases of the nanoparticles. Powder XRD data indicated a good match to the major reference peaks of $\mathrm{Au}$ and $\mathrm{Fe}_{3} \mathrm{O}_{4}$.

\section{The $\mathrm{A}^{3}$ coupling reaction:}

Benzaldehyde ( $1 \mathrm{mmol})$, piperidine $(1 \mathrm{mmol})$, and phenylacetylene $(1 \mathrm{mmol})$ were combined with either $\mathrm{Fe}_{3} \mathrm{O}_{4} @ \mathrm{Au}, \mathrm{Au}$ or $\mathrm{Fe}_{3} \mathrm{O}_{4}$ nanoparticles $(4 \mathrm{~mol} \%$ ) in toluene $(3 \mathrm{~mL})$ under a nitrogen atmosphere and refluxed for 48 hours in both the presence and absence of a magnetic field. The reaction mixture was collected at different time points $(3,6,12,24,36$, 42 and 48 hours), the catalyst was recovered by magnetic separation and the crude product was analyzed by ${ }^{1} \mathrm{H}$ NMR to determine the reaction conversion rate. Data is reported as an average \pm standard error mean $(\mathrm{n} \geq 2)$.

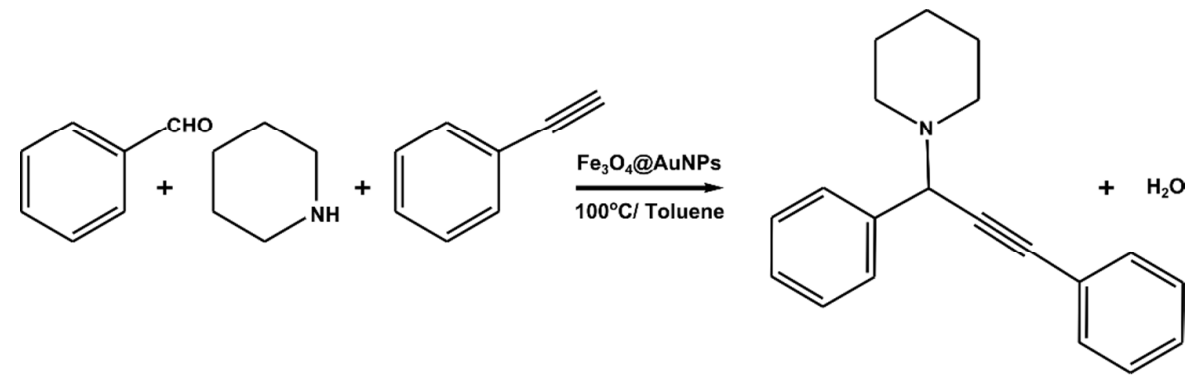

Scheme S1. A representative scheme of the $\mathrm{A}^{3}$-coupling reaction of benzaldehyde, piperidine, and phenylacetylene in toluene to yield propargylamine. 


\section{${ }^{1}$ H-NMR Analysis:}

The propargylamine product was analyzed by $1 \mathrm{D}{ }^{1} \mathrm{H}-\mathrm{NMR}$. All NMR experiments were performed at $298 \mathrm{~K}$ on Varian $400 \mathrm{MHz}$ NMR spectrometer.<smiles>C(#CC(c1ccccc1)N1CCCCC1)c1ccccc1</smiles>

N-(1, 3-Diphenyl-2-propynyl) piperidine.

$\mathrm{R}_{\mathrm{f}}=0.44$ (hexane: ethyl acetate: $9: 1$ )

${ }^{1}$ H NMR $400 \mathrm{MHz}\left(\mathbf{C D C l}_{3}\right) \boldsymbol{\delta}$ ppm: 7.66-7.63 (m, 2H), 7.54-7.50 (m, 2H), 7.37- 7.31 (m, $6 \mathrm{H}), 4.85(\mathrm{~s}, 1 \mathrm{H}), 2.64-2.57(\mathrm{~m}, 4 \mathrm{H}), 1.7-1.57(\mathrm{~m}, 4 \mathrm{H}), 1.5-1.4(\mathrm{~m}, 2 \mathrm{H})$.

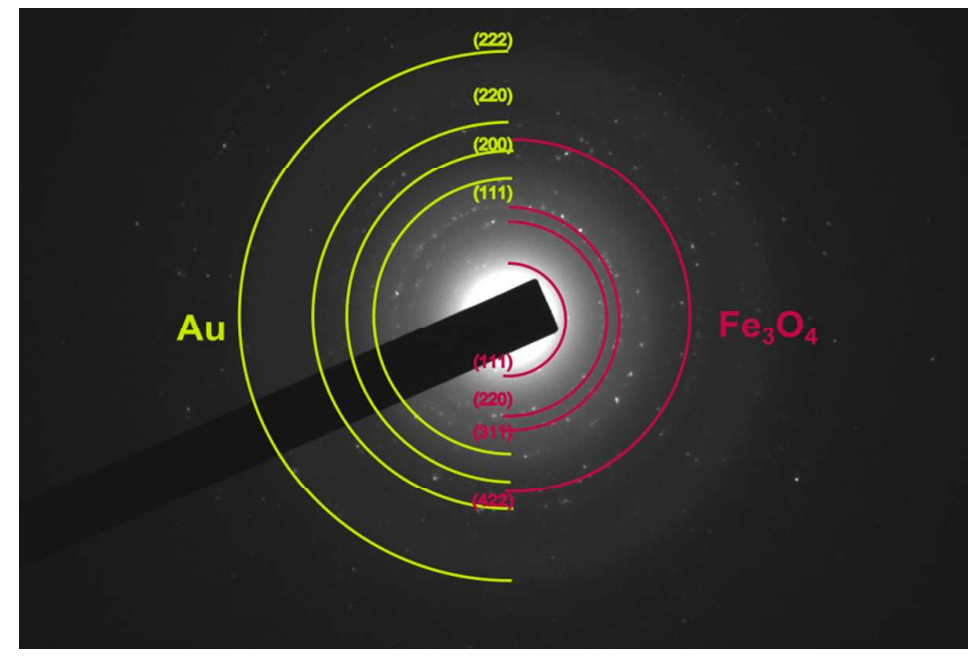

Figure S1. Electron diffraction of the $\mathrm{Fe}_{3} \mathrm{O}_{4} @ \mathrm{Au}$ chains as measured using energy-dispersive $\mathrm{X}$-ray spectroscopy on the FEI Titan G2 80-200 TEM/STEM. 


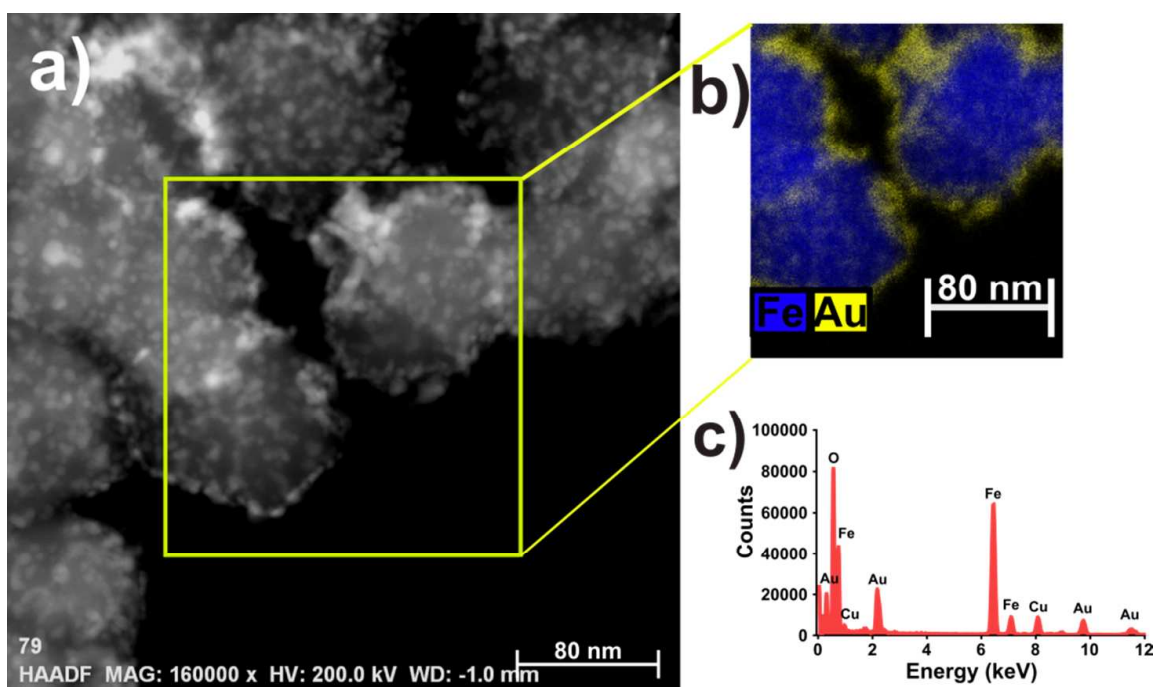

Figure S2. a) High-angle annular dark-field STEM image of Au seed functionalized $\mathrm{Fe}_{3} \mathrm{O}_{4}$-PEI nanoparticles; b) Energy dispersive X-ray microanalysis map of the specified region highlighting a Au (yellow) corona around Fe (blue) nanoparticles; c) Elemental analysis of the selected region demonstrating the presence of $\mathrm{Au}$ and $\mathrm{Fe}$. $\mathrm{The} \mathrm{Cu}$ signal is associated with the use of a copper grid in TEM analysis. 

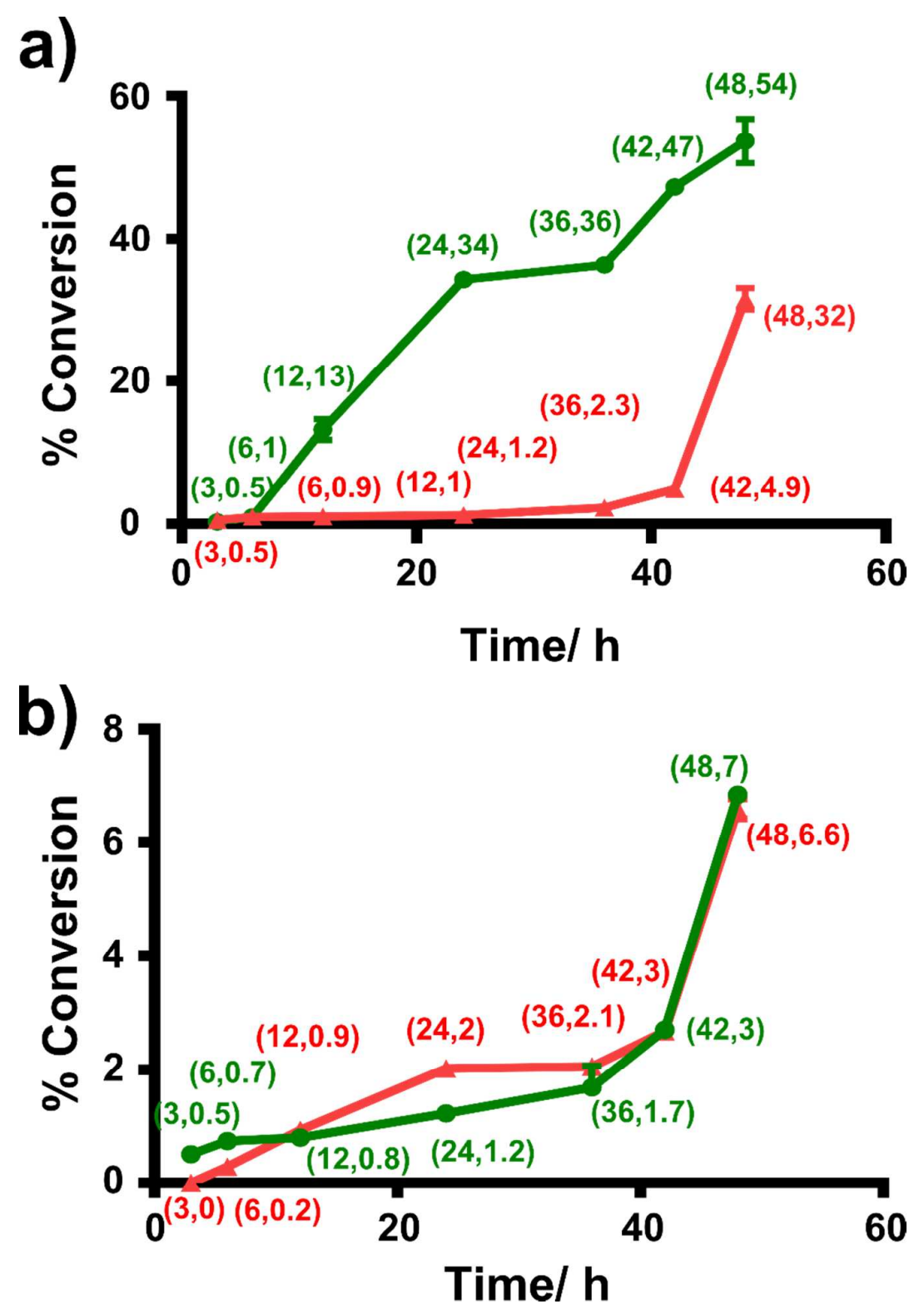

Figure S3. Rate of conversion ${ }^{\mathrm{a}}$ of the $\mathrm{A}^{3}$-coupling reaction in the absence (red) and presence (green) of an external magnetic field for a) $\mathrm{Fe}_{3} \mathrm{O}_{4}$ nanoparticles; and b) $\mathrm{Au}$ nanoparticles. Data are presented as mean \pm standard error mean $(n \geq 2)$. ${ }^{a}$ Conversion determined by ${ }^{1} \mathrm{H}$ NMR analysis of the crude reaction mixtures based on benzaldehyde conversion. 


\section{References:}

(1) Goon, I. Y.; Lai, L. M. H.; Lim, M.; Munroe, P.; Gooding, J. J.; Amal, R. Chem. Mat. 2009, 21, (4), 673-681.

(2) Brown, K. R.; Walter, D. G.; Natan, M. J. Chem. Mat. 2000, 12, (2), 306-313.

(3) Ho, D.; Peerzade, S. A. M. A.; Becker, T.; Hodgetts, S. I.; Harvey, A. R.; Plant, G. W.; Woodward, R. C.; Luzinov, I.; St. Pierre, T. G.; Iyer, K. S. Chem. Commun. 2013, 49, (64), 7138-7140. 